Revue d'histoire du XIXe siècle

Société d'histoire de la révolution de 1848 et des

révolutions du XIXe siècle

$52 \mid 2016$

Chrononymes. Dénommer le siècle

\title{
Damien BALDIN, Histoire des animaux domestiques,
} $X I X^{e}-X X^{e}$ siècles

Paris, Seuil, 2014

\section{Camille Lorenzi}

\section{(2) OpenEdition \\ Journals}

Édition électronique

URL : http://journals.openedition.org/rh19/5053

DOI : $10.4000 /$ rh 19.5053

ISSN : 1777-5329

Éditeur

La Société de 1848

\section{Édition imprimée}

Date de publication : 1 juin 2016

Pagination : 231-232

ISSN : 1265-1354

\section{Référence électronique}

Camille Lorenzi, «Damien BALDIN, Histoire des animaux domestiques, XIXe-XXe siècles », Revue d'histoire du XIXe siècle [En ligne], 52 | 2016, mis en ligne le 01 juin 2016, consulté le 23 septembre 2020. URL : http://journals.openedition.org/rh19/5053 ; DOI : https://doi.org/10.4000/rh19.5053

Ce document a été généré automatiquement le 23 septembre 2020

Tous droits réservés 


\section{Damien BALDIN, Histoire des animaux domestiques, $\mathrm{XIX}^{e}-\mathrm{XX}$ siècles}

Paris, Seuil, 2014

Camille Lorenzi

\section{RÉFÉRENCE}

Damien BALDIN, Histoire des animaux domestiques, XIX ${ }^{e}-X^{e}$ siècles, Paris, Seuil, 2014, 382 p., 22,50 euros.

1 Les animaux occupent une place structurante dans la société française du XIX ${ }^{\mathrm{e}}$ siècle : de par leur omniprésence sur le territoire et leur importance au sein de la vie économique et sociale d'une part ; à travers le discours à caractère affectif et politique qui se constituent à leur propos d'autre part. Partant de ce constat, Damien Baldin entend étudier le lien de domestication que l'homme instaure avec les animaux : ceuxci sont dès lors définis par ce statut de «domestique » qui leur est conféré. Damien Baldin se fonde pour cela sur les formes sociales et culturelles des pratiques et des discours qui sous-tendent ce lien de domestication. L'auteur s'approprie à travers son étude un objet qui avait suscité à l'origine un intérêt anthropologique, pour l'introduire au sein d'une historiographie française contemporaine qui l'avait jusqu'ici délaissé. En se fondant sur une lecture des imprimés professionnels, de la littérature romanesque, des archives provenant d'associations spécialisées et d'archives judiciaires, l'auteur met en lumière les tendances profondes de la domestication en France entre la fin du XVIII ${ }^{e}$ et les années 1950. Quatre grandes évolutions ressortent de l'ouvrage : un renforcement $\mathrm{du}$ lien entre les hommes et les animaux domestiques ; un encadrement plus fort de ces derniers ; la naissance d'une volonté de protection envers les animaux domestiques, parallèlement à un développement des procédés d'enfermement et d'exclusion des animaux qui sortent de cette catégorie.

2 Tout d'abord, l'augmentation numérique des animaux domestiques dans les villes et dans les campagnes s'accompagne d'une proximité physique plus forte, qui se double 
d'un sentiment d'attachement, entre les animaux et les hommes. Se crée dès lors une familiarité entre eux, familiarité renforcée par les évolutions socio-structurelles en œuvre tout au long du siècle. Le XIX ${ }^{\mathrm{e}}$ siècle est par exemple le siècle du repli sur la sphère privée: l'animal voit sa position renforcée dans un intérieur de plus en plus séparé de l'espace extérieur urbain. Les animaux de la maison se distinguent alors des animaux de la ville pour devenir des animaux de compagnie, qui vivent dans une intimité corporelle et sentimentale avec les hommes du foyer.

Cette familiarité avec les animaux participe d'un autre mouvement, celui de leur domination technique et leur amélioration physiologique. L'animal familier est aussi un animal dressé et dominé par l'homme. Deux animaux ressortent dans l'ouvrage, comme étant l'objet d'une attention particulière : le cheval et le chien. Dans les deux cas, le dressage doit aboutir à une obéissance complète de l'animal. Il est intéressant encore une fois de voir l'imbrication entre les évolutions du processus de domestication et les évolutions politiques et sociales de l'époque : la connaissance scientifique des animaux poussée au plus loin s'intègre dans une étude des races animales, parallèle à celle des races humaines, qui prend alors une importance scientifique déterminante. La hiérarchie animale devient le reflet de la hiérarchie humaine, ce qui inscrit les animaux dans une symbolique politique.

Cette domination de l'homme, loin de tracer une ligne de séparation entre les hommes et les animaux, renforce la familiarité et l'attention qui est portée à ces derniers. Se développe en particulier une volonté de protéger les animaux domestiques de la violence humaine. Ce mouvement correspond à deux évolutions plus larges: une sensibilité qui supporte de moins en moins la violence envers des êtres susceptibles de souffrir; l'importance économique des animaux, dont la productivité pourrait être remise en question par de mauvais traitements. Damien Baldin explique ainsi le vote de la loi Grammont en 1850 : cette loi, en punissant les violences commises envers les animaux, vise à canaliser une violence crainte à cette époque, qui est en réalité celle du sous-prolétariat. La protection des animaux est donc avant tout un problème de relation à l'humanité.

Le XIX ${ }^{e}$ siècle est celui de la domestication et de la familiarisation des animaux, mais il est aussi celui de leur contrôle. Cette évolution correspond à une tendance qui se renforce au sein des sensibilités citadines : la ville doit être un environnement sain, sûr et tranquille. Dès lors, tout animal qui menace cet état de chose est considéré comme nuisible et doit être écarté voire éliminé. Cela passe entre autres par un éloignement des nuisances animales : celui des abattoirs par exemple, qui remplacent les tueries du centre-ville. On repousse le cadavre malodorant, la carcasse porteuse potentielle de maladie, le sang qui dérange et le spectacle de la violence et de la mort - le paysage urbain devient calme et silencieux, ce qui est l'objectif des politiques hygiénistes de l'époque, qui cherchent à assainir l'environnement et à adoucir les mœurs. La ville se débarrasse et la ville enferme. Se dessine dès lors une nette frontière entre les animaux domestiques, qui sont de plus en plus attachés à leur maître, et les animaux errants indésirables, à l'identité vague à l'image des vagabonds.

6 La grande richesse de cet ouvrage capital est de replacer l'histoire animale et les étapes de la domestication au sein des grandes évolutions qui affectent la société. Damien Baldin se place ainsi volontairement en dehors du tournant des animal studies nées en Angleterre et aux États-Unis : à leur instar, il considère les animaux comme des objets culturels à part entière mais sans chercher à se placer de leur point de vue, dans une 
démarche qui ne serait plus anthropocentrée. Il s'agit pour l'auteur de conserver le point de vue imposé par les sources, et d'insister sur ce que la proximité des hommes et des animaux a apporté au vécu des uns et des autres. 